\title{
O Modelo de Tomasello sobre a Evolução Cognitivo-Linguística Humana'
}

\author{
Sylvio Állan² \\ Carlos Barbosa Alves de Souza \\ Universidade Federal do Pará
}

\begin{abstract}
RESUMO - O presente trabalho buscou apresentar o modelo de Michael Tomasello sobre a evolução da cognição humana e uma teoria, derivada desse modelo, sobre a aquisição e o desenvolvimento de competências linguístico-simbólicas. Tomasello propõe que a aquisição e o desenvolvimento simbólico dependem de uma cognição cultural exclusivamente humana, mas derivada de adaptações biológicas características da cognição primata. Essas propostas constituem alternativas para as abordagens tradicionais do desenvolvimento cognitivo e linguístico-simbólico humano, uma vez que: (1) destacam aspectos biológicos e culturais como determinantes da cognição humana; (2) consideram as atividades humanas como essencialmente simbólicas; (3) fornecem uma nova concepção de linguagem.
\end{abstract}

Palavras-chave: evolução; cognição humana; linguagem; primatas; Tomasello.

\section{Tomasello’s Approach of the Evolution of Human Cognition and Language}

\begin{abstract}
The present paper aimed to present Tomasello's approach about human-cognition evolution and a derived theory of acquisition and development of linguistic-symbolic competences. Tomasello proposes that symbolic acquisition and development depend on an exclusively human cultural cognition derived, however, from primate biological adaptations. These approaches represent some alternatives to traditional treatments for human cognitive and linguistic-symbolic development, considering that they: (1) highlight biological and cultural features as determinants of human cognition; (2) consider human activities as essentially symbolic; (3) offer a new conception of language.
\end{abstract}

Keywords: evolution; human cognition; language; primates; Tomasello.

A linguagem simbólica, enquanto relação mediada, convencionalmente estabelecida, representa um grande diferencial para as possibilidades de interação do ser humano com seu ambiente, comparativamente às demais espécies (Hauser, Chomsky \& Fitch, 2002; Tomasello \& Call, 1997).

A maior parte dos estudos sobre linguagem simbólica tem se voltado para os processos de aquisição e desenvolvimento de competências linguísticas e podem ser historicamente agrupados sob duas perspectivas: (a) estruturalista, que considera as competências linguísticas produto de estruturas biológico-cognitivas (específicas ou não para a linguagem simbólica) e tem se concentrado na análise das propriedades estruturais da linguagem simbólica (gramaticais, sintáxicas, fonéticas, semióticas) e na derivação de regras linguísticas gerais; (b) funcionalista, que define as competências linguísticas em termos de relações funcionais estabelecidas entre os indivíduos e o mundo e busca analisar os aspectos pragmáticos da linguagem simbólica. Ambas as perspectivas têm abordado a linguagem simbólica em diferentes níveis de

1 O presente trabalho é derivado da dissertação de mestrado do primeiro autor, sob orientação do segundo autor, apresentada ao Programa de Pós-Graduação em Teoria e Pesquisa do Comportamento, da Universidade Federal do Pará, em 2007, com apoio do Conselho Nacional de Desenvolvimento Científico e Tecnológico (CNPq), por meio de bolsa de estudo.

2 Endereço para correspondência: Rua Manoel Barata, 106, Apartamento 202, Cruzeiro, Distrito de Icoaraci. Belém, PA. CEP 66.810-100. Email: sylvioallan@yahoo.com.br, carlos.souza@pesquisador.cnpq.br. análise; todavia, elas têm se confrontado com dificuldades conceituais e metodológicas (Souza, 2001, 2003; Souza \& Pontes, 2007).

Uma proposta funcionalista recente que vem abordando repertórios complexos (e.g., gramaticalização e repertório narrativo) na investigação dos processos de aquisição e desenvolvimento da linguagem simbólica é a "teoria da aquisição da linguagem baseada no uso" ou "linguística cognitivo-funcional” (Tomasello, 2003b), que enfatiza aspectos biológicos e sócio-pragmáticos envolvidos nos processos de aquisição e desenvolvimento de competências linguísticas. Sua hipótese central é a de que a aquisição e o desenvolvimento de competências linguísticas humanas são processos sócio-biológicos envolvendo habilidades sociocognitivas humanas de compreensão e compartilhamento de intencionalidade e a participação em atividades sóciocomunicativas, historicamente estabelecidas, com indivíduos humanos linguística e simbolicamente competentes.

As principais características dessa teoria são: (1) a ênfase na aquisição e no desenvolvimento da linguagem simbólica, sem a recorrência a padrões estruturais (Chomsky, 1959/1967, 1968, 1980; Pinker, 1994); (2) a ênfase em construções e sentenças linguísticas inteiras - e não em palavras isoladas e/ou morfemas, uma característica das teorias estruturalistas da linguagem - como unidades efetivas da aquisição da linguagem simbólica; (3) a ênfase na aquisição de estruturas linguísticas (e.g., gramaticalização/ sintaxização), por meio de práticas discursivas ontológica e historicamente estabelecidas. 
A teoria da aquisição da linguagem baseada no uso vem sendo desenvolvida no interior de uma análise mais ampla sobre a evolução da cognição humana (Tomasello, 1999/2003a; Tomasello, Carpenter, Call, Behne \& Moll, 2005a, 2005b). Essa análise tem proposto que a cognição humana é o produto co-evolutivo de adaptações biológicas específicas à cognição primata e de atividades de colaboração relacionadas à cognição cultural (e.g., a criação e o uso de símbolos linguísticos e matemáticos, artefatos culturais, tecnologias, práticas culturais e instituições sociais).

Esse modelo de evolução da cognição humana tem buscado conciliar, em um mesmo quadro conceitual, aspectos filogenéticos, ontogenéticos e culturais (Tomasello, 1999/2003a), ao mesmo tempo em que critica a prática tradicional, dentro das ciências humanas e sociais, de se estabelecer uma cisão entre os aspectos biologicamente herdados e os culturalmente aprendidos, ao abordar-se a cognição humana.

Com base nisso, o objetivo do presente trabalho é: (1) apresentar o modelo de Tomasello sobre a evolução da cognição humana e a sua teoria da aquisição da linguagem baseada no uso, identificando suas principais características; (2) descrever como essas propostas estão relacionadas entre si e inseridas em um mesmo sistema de referência teóricoconceitual desenvolvido por Tomasello.

\section{Evolução Cultural}

Tomasello (1999/2003a, 2003b) questionou a hipótese de que as habilidades socio-cognitivas humanas sejam produtos diretos da evolução biológica (Pinker, 1994); segundo ele, o período que separa a linha evolutiva das espécies hominídeas e primatas (de 2 a 6 milhões de anos, aproximadamente) é um tempo evolutivo relativamente curto para que essas habilidades pudessem ter sido selecionadas pelos mecanismos de variação genética e pela seleção natural. Além disso, somente nos últimos 200 mil anos, a espécie humana teria começado a desenvolver complexas formas de tecnologia de ferramentas, de comunicação e representação simbólica, assim como de organizações e práticas sociais.

Isso sugere um mecanismo evolutivo que teria operado mais rapidamente e em um tempo cronologicamente mais curto do que a seleção natural. Uma hipótese (Tomasello, 1999/2003a) é a de que as habilidades socio-cognitivas humanas são produtos de uma evolução cultural, que opera em um tempo cronológico menor devido a um mecanismo de transmissão cultural, que permitiria que habilidades e conhecimentos já existentes em certa cultura (humana ou não-humana) fossem transmitidos para os membros pertencentes à mesma cultura.

A transmissão cultural inclui coisas como um filhote de passarinho imitar o canto típico da espécie cantado por seus pais, filhotes de rato comerem apenas os alimentos comidos por suas mães, formigas localizarem comida seguindo os rastros de feromônio dos co-especificos, jovens chimpanzés aprenderem as práticas de uso de ferramentas dos adultos com quem convivem, e crianças humanas adquirirem as convenções linguísticas dos outros membros de seu grupo social. (Tomasello, 1999/2003a, p. 5)
No entanto, ainda que a transmissão cultural seja um mecanismo comum a uma grande variedade de espécies animais (incluindo a espécie humana), as tradições culturais humanas teriam se apoiado em processos socio-cognitivos e de aprendizagem cultural diferentes daqueles supostamente responsáveis pelas tradições culturais não-humanas, especificamente, envolvendo produtos culturais (e.g., práticas e artefatos culturais) modificados e acumulados ao longo da evolução histórica.

Essa forma de transmissão cultural caracteristicamente humana teria possibilitado que os indivíduos: (1) se beneficiassem dos conhecimentos adquiridos por gerações anteriores, sem a necessidade de consumir o mesmo tempo ou esforço que aqueles; (2) promovessem modificações nesses conhecimentos; e (3) transmitissem esses conhecimentos modificados para gerações posteriores.

Como consequência da evolução cultural humana, algumas habilidades cognitivas e socio-cognitivas já existentes na espécie humana teriam sido alteradas significativamente, produzindo uma cognição humana propriamente dita. Contudo, essa mesma evolução cultural somente teria se tornado possível devido à diferenciação dessas habilidades cognitivas e socio-cognitivas em relação à cognição primata (Tomasello, 1999/2003a).

\section{Modelo de Evolução da Cognição Humana}

\section{Cognição humana e filogênese}

Do ponto de vista filogenético, Tomasello (1999/2003a) propôs que a cognição humana teria se desenvolvido a partir de um conjunto de habilidades socio-cognitivas primatas relacionadas à atribuição de intencionalidade a co-específicos (denominadas compreensão da ação intencional). Essas habilidades teriam possibilitado à espécie humana uma maior flexibilidade comportamental e criatividade na resolução de problemas (e.g., previsão, controle e alteração de eventos), e favorecido certas formas de aprendizagem cultural e de sociogênese (i.e., transformações nas estruturas sociais) que estariam diretamente relacionadas ao mecanismo de transmissão cultural caracteristicamente humana.

A compreensão da ação intencional consiste fundamentalmente: (1) na participação em atividades de atenção conjunta com co-específicos em relação a aspectos do mundo (Bakeman \& Adamson, 1984); (2) no monitoramento da atenção e dos gestos de co-específicos em relação a aspectos do mundo; (3) na manipulação da atenção de co-específicos, por meio de gestos não-linguísticos, em relação a aspectos do mundo; e (4) na compreensão e imitação das ações e atos de fala de co-específicos em relação a aspectos do mundo e a si mesmo (Tomasello, Kruger \& Ratner, 1993).

A compreensão da ação intencional teria sido derivada de adaptações biológicas presentes na cognição dos primatas em geral, especificamente: (1) da compreensão de categorias relacionais externas (Tomasello \& Call, 1997) entre coespecíficos (e.g., parentesco, dominância) e entre eventos (e.g., contiguidade, tamanho, posição); (2) da compreensão dos aspectos intencionais (e.g., intenções, estados emocionais 
e percepções) mediadores das relações sociais, e dos aspectos causais (e.g., força, resistência, pressão) mediadores das relações físicas (Tomasello \& Call, 1997; Tomasello, Kruger \& Ratner, 1993); e (3) da habilidade de ação intencional (i.e., compreender que suas próprias ações são distintas dos resultados dessas ações e compreender que ações específicas estão relacionadas a resultados específicos).

Além dessas adaptações, a compreensão da ação intencional teria evoluído de uma predisposição primata para identificar-se com co-específicos, o que teria possibilitado aos primatas atribuir aos seus co-específicos características intencionais já reconhecidas em si mesmos, pela ação intencional, e compreender as ações dos seus co-específicos em termos intencionais. Deve-se ressaltar, contudo, que o conceito de predisposição para identificação com co-específicos não foi adequadamente desenvolvido na proposta de Tomasello, seja pela falta de esclarecimentos sobre os processos pelos quais essa característica teria evoluído - e, consequentemente, se ela é uma adaptação biológica ou um produto cultural -, seja pela falta de evidências empíricas que sustentem essa hipótese.

Contudo, uma vez que tanto a cognição humana quanto a cognição primata não-humana compartilham as habilidades de compreensão da ação intencional, deve-se considerar que essas habilidades são uma condição necessária, porém, não-suficiente para a constituição da cognição humana propriamente dita.

Tomasello e cols. (2005b) propuseram que o evento crítico para a diferenciação entre a cognição humana e a cognição primata é uma motivação exclusivamente humana para compartilhar intencionalidade (i.e., apresentar estados psicológicos que correspondam aos estados psicológicos dos outros, como por exemplo, ações, intenções, percepções, objetivos e estados emocionais) com outros indivíduos humanos. Como consequência disso, a espécie humana teria desenvolvido complexas formas de colaboração caracteristicamente humana que resultaram nas organizações culturais humanas modernas. No caso dos primatas não-humanos (e dos humanos autistas), essa motivação para compartilhar intencionalidade parece não existir.

A hipótese de Tomasello e cols. (2005b) da intencionalidade compartilhada foi criticada em diferentes níveis. Questionou-se a hipótese de uma adaptação biológica específica para a intencionalidade compartilhada e para a compreensão da ação intencional, sugerindo-se que essas características humanas são produtos culturais (Bruner, 2005), ou derivadas de outras habilidades cognitivas (Watson, 2005), ou que se desenvolvem diferencialmente entre os indivíduos (Brownell, Nichols \& Svetlova, 2005).

Questionou-se, inclusive, a hipótese de que a intencionalidade compartilhada fosse uma característica exclusivamente humana, a partir de evidências empíricas que sugeriram que primatas não-humanos também possuem intencionalidade compartilhada (Boesch, 2005; Horner, Bonnie \& de Waal, 2005), mas que diferenças qualitativas nas habilidades de colaboração, cognição e cultura entre as espécies humanas e primatas não-humanas estão relacionadas: (1) às diferenças nos processos básicos (Hatano \& Takahashi, 2005); (2) à habilidade humana de representar seus próprios comportamentos e os comportamentos dos outros em termos de estados mentais e, consequentemente, de compartilhar estas representações (Povinelli \& Barth, 2005); ou (3) às habilidades linguísticas humanas (Schuster, 2005).

Em adição, o conceito de motivação não foi adequadamente definido por Tomasello e cols. (2005b), nem foram fornecidas evidências empíricas que confirmassem esse fenômeno ou esclarecessem como essa motivação levaria ao compartilhamento de intenções (Gauvain, 2005).

\section{Cognição humana e ontogênese}

A compreensão da ação intencional, embora considerada uma adaptação biológica no modelo de Tomasello, não surgiria imediatamente e nem plenamente desenvolvida logo após o nascimento do bebê humano. Na verdade, ela é o resultado de um processo gradual de organização das ações sensório-motoras do bebê humano (e.g., pela imitação do comportamento dos adultos) e de identificação com seus co-específicos (e.g., sob a forma de mímicas neonatais e protoconversações ${ }^{3}$ ), culminando na sua formação propriamente dita por volta dos 9 meses de idade (Tomasello, 1999/2003a).

Tomasello e cols. (2005b) categorizaram três níveis de compreensão da ação intencional durante o desenvolvimento ontogenético humano (ver Figura 1):

a) Compreensão da ação animada. Por volta dos seus 6 meses de vida, crianças compreendem seus co-específicos como sendo capazes de ação espontânea, e podem acompanhar-lhes a direção da ação e construir suas próprias experiências em termos de expectativas da ação em contextos familiares (Bertenthal, 1996; D’Entremont, Hains \& Muir, 1997; Woodward, 1998). Um aspecto do comportamento da criança durante esse período é a sua relação diádica com o ambiente físico e social;

b) Compreensão da ação orientada para objetivos. Por volta dos seus 9 meses de vida, crianças começam a apresentar um padrão de cognição social diferenciado em relação aos primatas não-humanos. Elas passam a compreender seus coespecíficos como sendo capazes de realizar ações específicas para produzir objetivos específicos (Baldwin, Baird, Saylor \& Clark, 2001; Behne, Carpenter, Call \& Tomasello, 2005; Bellagamba \& Tomasello, 1999; Carpenter, Akhtar \& Tomasello, 1998; Meltzoff, 1995; Moll \& Tomasello, 2004);

c) Compreensão do planejamento de ações. Por volta dos seus 14 meses de vida, as crianças começam a compreender seus co-específicos como sendo capazes de selecionar planos de ação para produzir objetivos em contextos específicos. Elas também são capazes de se engajar em formas de aprendizagem cultural, prevendo as ações dos seus co-específicos e aprendendo a fazer coisas convencionalmente estabelecidas em uma cultura (Gergely, Bekkering \& Kiraly, 2002; Tomasello \& Haberl, 2003).

Durante o seu primeiro ano de vida, com o desenvolvimento das habilidades de compreensão da ação intencional e a motivação para compartilhar intencionalidade, as crianças também passam a compartilhar com os adultos certos

3 Interações baseadas em uma atenção dirigida para expressar e compartilhar emoções básicas (ver Tomasello, 1999/2003a, 2003b). 


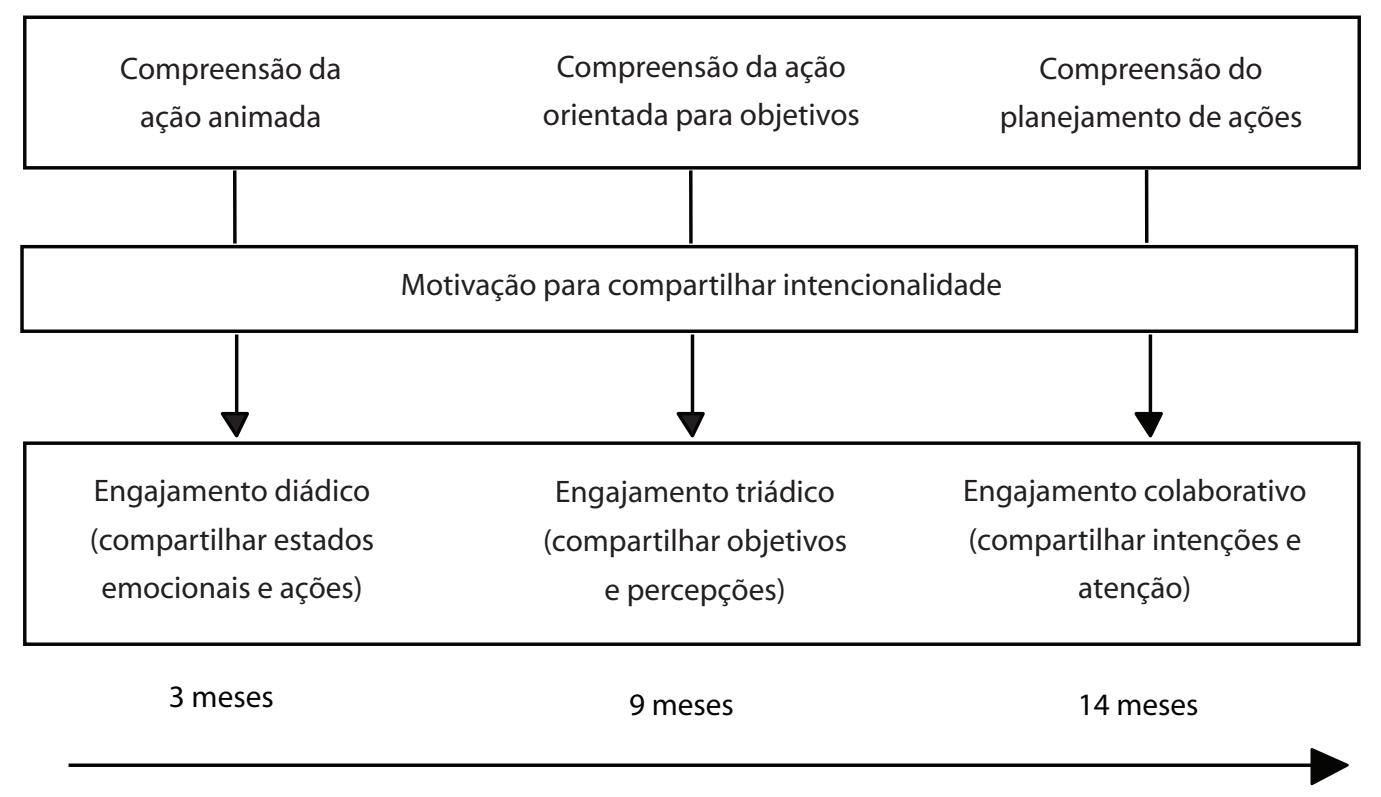

Figura 1. Esquema do desenvolvimento da compreensão da ação intencional e da intencionalidade compartilhada, durante o primeiro ano de vida da criança. O primeiro quadro indica os três níveis de compreensão da ação intencional. O segundo quadro indica a motivação para compartilhar intencionalidade. O terceiro quadro indica os níveis de intencionalidade compartilhada e abaixo está indicada a idade da criança (Fonte: Tomasello \& cols., 2005b; versão modificada do original).

aspectos de sua própria experiência. Essa nova forma de interação com o mundo (intencionalidade compartilhada) é caracterizada em três níveis:

a) Engajamento diádico. Por volta dos seus 6 meses de vida, crianças compartilham, com seus co-específicos, ações e estados emocionais;

b) Engajamento triádico. Por volta dos seus nove 9 meses de vida, crianças compartilham, com seus co-específicos, objetivos, ações e percepções uns dos outros;

c) Engajamento colaborativo. Por volta dos seus 14 meses de vida, crianças compartilham, com seus co-específicos, estados intencionais e percepções, e adotam uma ação conjunta para atingir um objetivo compartilhado. É pelo engajamento da criança em atividades colaborativas, a partir desse período, que ocorrerão formas únicas de interação social, aprendizagem cultural, comunicação simbólica e representação cognitiva.

É também pelo engajamento colaborativo que as crianças aprendem a internalizar ${ }^{4}$, sob a forma de representações cognitivas dialógicas ${ }^{5}$, as perspectivas dos adultos e a utilizá-las para mediar sua compreensão do mundo e da cultura humana.

4 O conceito de internalização utilizado por Tomasello (1999/2003a) parece se aproximar do sentido vygotskiano, em termos de uma relação de subjetivação de símbolos estabelecidos culturalmente. A diferença entre esses conceitos parece ser o destaque que Tomasello e cols. (2005b) deram para a internalização como representações cognitivas.

5 Alguns autores (e.g., Zlatev, Persson \& Gärdenfors, 2005) questionaram a falta de elaboração do conceito de representações cognitivas dialógicas na proposta de Tomasello e cols. (2005b), do processo ontogenético de construção dessas representações e das implicações cognitivas de se operar com elas (Fernyhough, 2005), assim como a falta de evidências de como essas representações poderiam orientar a compreensão da ação intencional (Perner \& Doherty, 2005).
Essas representações são importantes tanto para as interações colaborativas quanto para a criação e utilização de artefatos culturais (e.g., símbolos linguísticos), pois permitem que as crianças sejam capazes de construir normas socialmente generalizadas que tornam possíveis a conceitualização e o compartilhamento de crenças individuais, e a criação de fatos sócio-institucionais (e.g., dinheiro, casamento, governo), baseados em práticas e crenças coletivas de um grupo social (Tomasello, 1999/2003a).

No caso das crianças autistas, Tomasello e cols. (2005b) afirmaram que, embora elas compreendam certos aspectos da ação intencional, e, portanto, possuam algumas habilidades de aprendizagem social, não há evidências de que elas sejam capazes de se engajar em atividades diádicas, triádicas e colaborativas, do mesmo modo que as crianças normais. Provavelmente isso estaria relacionado à falta de motivação das crianças autistas para compartilhar intencionalidade com seus co-específicos, o que as tornariam limitadas para criar coisas culturalmente com outros indivíduos.

Essa hipótese motivacional para o déficit cognitivo de crianças autistas foi criticada, propondo-se alternativamente que este poderia estar relacionado ao déficit de outras habilidades (Charman, 2005). Algumas evidências sugerem também que crianças portadoras de autismo são capazes de compartilhar intencionalidade e que o seu déficit cognitivo se deve à ausência de habilidades perceptuais que possibilitem a compreensão dos estados psicológicos de si mesmo e de co-específicos em contextos sociais complexos (Verbeke \& cols., 2005).

Ainda em relação ao conceito de engajamento colaborativo na proposta de Tomasello e cols. (2005b), Brownell e cols. (2005) afirmaram que esse conceito se baseia em interações criança-adulto, mas que evidências sobre interações criança- 
Situação Perceptual

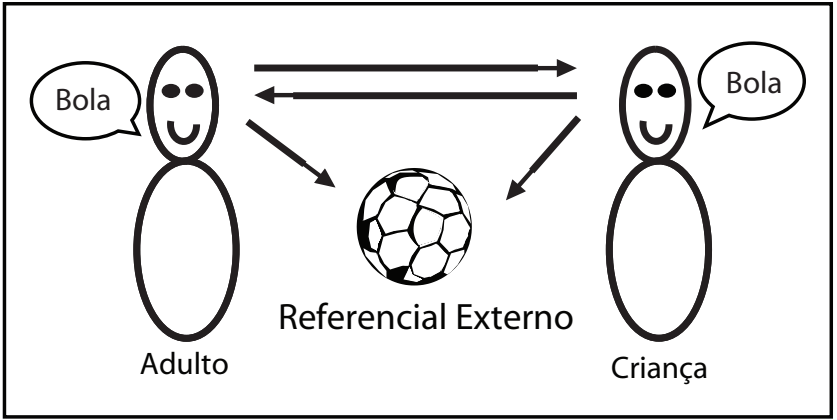

Figura 2. Esquema da interação criança-adulto em um quadro de atenção conjunta. A criança percebe um referencial externo, percebe o adulto percebendo o mesmo referencial externo e percebe o adulto percebendo ela mesma como referencial externo. A mesma situação ocorre com o adulto (Fonte: Tomasello, 2003b; versão modificada do original).

criança sugerem que atividades de colaboração surgem somente ao final do segundo ano de vida e que a compreensão da ação intencional também se desenvolve relativamente mais tarde do que o proposto por Tomasello e cols. Por outro lado, Vaish e Woodward (2005) descreveram evidências que sugerem que crianças compreendem adultos como agentes orientados para objetivos e representam algumas ações como orientadas para objetivos antes dos 9 meses de vida; e que a partir dessas representações, as crianças aprendem relações entre ações e relações entre ações e objetos externos.

\section{Teoria da Aquisição da Linguagem Baseada no Uso}

Um aspecto pelo qual a proposta de Tomasello distingue-se das abordagens tradicionais da cognição humana (Bickerton, 2005) é por não enfatizar a linguagem como o aspecto crítico para a evolução da cognição humana, mas, inversamente, sugerir que ela é um produto desse tipo de cognição.

Com o desenvolvimento das habilidades de compreensão da ação intencional e a motivação humana para compartilhamento de intencionalidade, a partir dos seus 9 meses de vida, a criança começa a se engajar triadicamente com adultos linguística e simbolicamente competentes em contextos intersubjetivos (compartilháveis entre indivíduos), nos quais tanto ela quanto o adulto compartilham experiências de atenção conjunta em relação a referenciais externos. ${ }^{6}$ Esse padrão de interação social é denominado quadro de atenção conjunta (Tomasello, 1999/2003a, 2003b) (ver Figura 2).

Especificamente, quadros de atenção conjunta se manifestam: (1) no monitoramento da atenção dos adultos e da própria criança para referenciais externos; (2) na utilização dos adultos como ponto de referência em relação a referen-

6 Outra condição que teria favorecido a aquisição e o desenvolvimento de competências linguísticas refere-se às habilidades cognitivas primata de busca de padrão, que emergem durante os primeiros meses de vida da criança. Essas habilidades permitiriam à criança identificar padrões nos modos como os adultos utilizam os símbolos linguísticos e, consequentemente, como se constroem relações gramaticais. (Tomasello, 2003b). ciais externos (referência social); (3) na imitação do modo de interação dos adultos com referenciais externos (aprendizagem por imitação); e (4) na interação conjunta da criança com o adulto, mediada por referenciais externos.

Nos quadros de atenção conjunta, tanto a criança quanto $o$ adulto definem intencionalmente os referenciais externos e as atividades que compõem esses contextos. Além disso, a criança compreende o papel que ela, o adulto e o referencial externo desempenham nesses contextos, assim como a intercambialidade desses papéis, o que lhe permitirá adotar uma perspectiva externa para formar um autoconceito (Tomasello, 1999/2003a) ou para compreender as intenções do adulto ao utilizar símbolos linguísticos para manipular sua atenção (Tomasello, 2003b).

Simultaneamente à formação dos quadros de atenção conjunta, as crianças desenvolvem comportamentos comunicativos, sob a forma de gestos deícticos triádicos (i.e., referências demonstrativas feitas a elementos terceiros; Tomasello, 2003b). Esses têm por objetivo manipular a atenção dos adultos para referenciais externos, seja para alterá-los (gestos imperativos) ou simplesmente para indicá-los (gestos descritivos).

A compreensão que a criança tem dos papéis específicos que ela, o adulto e o referencial externo desempenham dentro de quadros de atenção conjunta lhe permite compreender as intenções comunicativas do adulto quando este utiliza símbolos linguísticos (palavra escrita ou falada) para manipular os estados intencionais da criança (Tomasello, 2003b). Uma vez que a criança somente é capaz de compreender e utilizar símbolos linguísticos quando ela compreende que os adultos utilizam símbolos linguísticos intencionalmente para atingir objetivos específicos, a compreensão da intenção comunicativa é uma condição necessária para a aquisição da linguagem (Tomasello, 1999/2003a, 2003b).

Se você vem e me empurra sobre uma cadeira, reconheço sua intenção de que eu me sente, mas se você me disser 'Sente-se!', reconhecerei sua intenção de que eu atenda a sua proposta de que eu me sente (...). Para entender que a intenção do outro é chutar uma bola, tenho apenas que determinar seu objetivo no que diz respeito à bola. Mas, para compreender o que outra pessoa pretende quando emite o som 'Bola' na minha direção, tenho de determinar seu objetivo no que diz respeito aos meus estados de atenção/intencionais em relação a uma terceira entidade. (Tomasello, 2003b, p. 143)

Portanto, enquanto a compreensão da ação intencional envolve a compreensão dos objetivos da ação do outro em relação a um referencial externo, a compreensão da intenção comunicativa envolve a compreensão dos objetivos do outro em relação a meus estados intencionais/atencionais. Nesse caso, é imprescindível que a criança tenha uma percepção de si mesma ao monitorar os estados intencionais dos outros em relação a ela.

A compreensão da intenção comunicativa pode ser aplicada às várias modalidades de proposições. Por exemplo, enquanto que o imperativo "Sente-se!" requer que o ouvinte compreenda a intenção do falante de que ele [o ouvinte] atenda ao imperativo, o declarativo "Isto é uma cadeira!" requer que o ouvinte compreenda a intenção do falante de 
que ele [o ouvinte] compartilhe a atenção com o falante em relação à cadeira, e o performativo “Obrigado!” requer que o ouvinte compreenda a intenção do falante de que ele [o ouvinte] atente para o estado emocional do falante (Tomasello, 1999/2003a, 2003b).

O importante é ressaltar que em todas essas situações, a compreensão da intenção comunicativa somente ocorre dentro de um contexto estabelecido pelos quadros de atenção conjunta. E que em cada um desses contextos, tanto a criança quanto o adulto compreendem as intenções do comportamento (compreensão da ação intencional) e do estado intencional um do outro (compreensão de intenções comunicativas) (Tomasello, 2003b).

À medida que a criança compreende as intenções comunicativas do adulto e a intercambialidade dos papéis exercidos dentro dos quadros de atenção conjunta, ela (a criança) passa a compreender que o adulto pode também compreender as suas intenções comunicativas. Consequentemente, ela passa a utilizar os mesmos símbolos linguísticos utilizados pelos adultos para atingir suas próprias intenções comunicativas (i.e., manipular os estados intencionais do adulto) (Tomasello, 1999/2003a, 2003b).

Portanto, os símbolos linguísticos são os meios arbitrariamente compartilhados (intersubjetivos) pela criança e pelo adulto, na medida em que ambos compreendem a qual função esses símbolos se prestam e qual o seu próprio papel (tanto da criança quanto do adulto) no quadro de atenção conjunta (Tomasello, 1999/2003a, 2003b; Tomasello \& cols., 2005b). Além da intersubjetivadade, os símbolos linguísticos possuem um caráter perspectivo, pois a criança aprende diversos modos de representar uma mesma coisa e de utilizar o mesmo meio para atingir objetivos diversos.

Na medida em que a criança passa a internalizar os símbolos linguísticos (constituídos de intenções comunicativas e das perspectivas dos adultos), ela se torna capaz de construir representações linguísticas mais complexas de cenas experienciais - por meio de construções linguísticas abstratas analógicas, metafóricas e de narrativas ${ }^{7}$ - que vão além do contexto imediato-perceptual.

\section{Cognição Humana, Linguagem e Cultura}

Tomasello propõe uma interdependência de processos filogenéticos, ontogenéticos e históricos para a formação da cognição humana. Segundo ele, certas habilidades cognitivas e socio-cognitivas humanas se desenvolvem durante o primeiro ano de vida da criança e favorecem a sua interação com indivíduos simbolicamente competentes. Como consequência dessa interação e da aquisição de um repertório simbólico (e.g., linguagem simbólica), ocorrem alterações significativas nessas habilidades, possibilitando novas formas de interação

7 Analogias e metáforas são categorias relacionais que permitem a utilização de uma construção linguística fora do seu contexto original para substituir outra, sem a perda da estrutura relacional original. Narrativas são encadeamentos de construções linguísticas complexas por meio de uma sequência logicamente coerente; neste sentido, as narrativas se distinguem de encadeamentos aleatórios de eventos (Tomasello, 1999/2003a). cultural, que por sua vez, retroagem sobre essas habilidades, modificando-as, e assim por diante.

Os processos sociais e culturais durante a ontogênese não criam as habilidades cognitivas básicas. O que fazem é transformar habilidades cognitivas básicas em habilidades cognitivas extremamente complexas e sofisticadas. (Tomasello, 1999/2003a, p. 264)

Embora Tomasello tenha destacado processos históricos universais como um dos responsáveis pelo desenvolvimento da cognição humana, ele não descarta a importância de aspectos culturais específicos (Tomasello, 1999/2003a), uma vez que esses aspectos estão geralmente relacionados com a utilização de símbolos linguísticos em interações discursivas, nas quais diferentes perspectivas são contrastadas e compartilhadas. Assim, essas interações representariam o principal veículo de transmissão cultural humana.

As práticas discursivas favoreceriam também: (1) a categorização e perspectivação conceitual de diferentes aspectos do mundo; (2) a conciliação de diferentes perspectivas (desacordos, mal-entendidos, solicitações de esclarecimento e conversas reflexivas); (3) a compreensão causal e certas formas de raciocínio quantitativo, que não são de origem sócio-cultural, mas que teriam assumido características humanas em função de um ambiente cultural e linguístico; e (4) a internalização das práticas discursivas e das instruções dos adultos em formatos dialógicos, como formas de autoregulação, metacognição e re-descrição comportamental ${ }^{8}$.

\section{Considerações Finais}

No presente trabalho, buscamos apresentar um modelo proposto por Tomasello sobre a evolução das habilidades cognitivas humanas e sua teoria da aquisição e desenvolvimento de repertórios linguísticos. Sugerimos que essas duas propostas constituem alternativas para as abordagens tradicionais do desenvolvimento cognitivo e linguístico-simbólico humano. Podemos sugerir pelo menos três contribuições principais dessas propostas.

Primeiro, elas buscam preencher as lacunas na história evolutiva da espécie humana, fornecendo subsídios que sugerem que, a despeito da sua grande complexidade e de suas características singulares, a cognição humana é um produto evolutivo derivado: (1) de uma base biológica comum a outras espécies, principalmente, a cognição primata; e (2) de um processo de evolução cultural. Com isso, elas destacam tanto aspectos biológicos quanto culturais como determinantes da cognição humana propriamente dita (Tomasello 1999/2003a).

Segundo, elas nos permitem considerar que, embora nem todas as atividades cognitivas humanas sejam simbólicas (e.g., percepção, categorização, memorização), as atividades exclusivamente humanas imprescindem de símbolos e cons-

8 Auto-regulação é a habilidade de controlar suas próprias ações. Metacognição é a habilidade de compreender os processos de conhecimento de si mesmo e de outros. Re-descrição comportamental é descrever o seu próprio comportamento e de outros, a partir de informações anteriores acerca desse comportamento. 
truções linguísticos, padrões discursivos intersubjetivos e perspectivos, e de um ambiente cultural onde a criança aprende a utilizá-los devido às interações contínuas com adultos simbolicamente competentes. Nesse sentido, podemos dizer que a cultura humana é intrinsecamente simbólica.

Terceiro, elas fornecem uma concepção de linguagem simbólica que favorece o estudo de uma variedade de repertórios verbais complexos que, de forma geral, não vinham sendo investigados pelas abordagens funcionalistas da linguagem simbólica, além de investigar processos simbólicos mais complexos do que aqueles tradicionalmente investigados por essas abordagens.

No entanto, como visto anteriormente, essas propostas têm recebido diversas críticas, sendo as mais comuns aquelas dirigidas à sua ênfase na compreensão e no compartilhamento da intencionalidade como elementos fundamentais para o desenvolvimento cognitivo e linguístico-simbólico humano. Especificamente, as críticas a esses aspectos estão relacionadas, principalmente, à necessidade de um melhor esclarecimento do conceito de intencionalidade. Do nosso ponto de vista, consideramos que a falta de clareza no tratamento do conceito de intencionalidade (e de outros conceitos relacionados a este, como motivação e representações cognitivas dialógicas) pode ser problemática por sugerir um retorno às propostas mentalistas sobre a cognição, em geral, e sobre a linguagem simbólica, em particular.

Além disso, algumas evidências empíricas têm questionado alguns dados apresentados por Tomasello como suporte às hipóteses do desenvolvimento de habilidades socio-cognitivas de compreensão da ação intencional e do compartilhamento de intencionalidade durante os primeiros anos de vida da criança (Boesch, 2005; Brownell \& cols., 2005; Brownell, Nichols \& Svetlova, 2005; Bruner, 2005; Charman, 2005; Hatano \& Takahashi, 2005; Horner, Bonnie \& de Waal, 2005; Povinelli \& Barth, 2005; Schuster, 2005; Vaish \& Woodward, 2005; Verbeke \& cols., 2005; Watson, 2005).

Considerando as críticas dirigidas especificamente ao desenvolvimento conceitual no contexto dessas propostas de Tomasello, buscaremos apresentar em um trabalho posterior uma interpretação alternativa dos conceitos utilizados por Tomasello, a fim de tentar avaliar a validade dessas críticas e/ou sugerir reformulações no tratamento desses conceitos.

\section{Referências}

Bakeman, R., \& Adamson, L. B. (1984). Coordinating attention to people and objects in mother-infant and peer-infant interaction. Child Development, 55(4), 1278-1289.

Baldwin, D. A., Baird, J. A., Saylor, M. M., \& Clark, M. A. (2001). Infants parse dynamic action. Child Development, 72(3), 708-717.

Behne, T., Carpenter, M., Call, J., \& Tomasello, M. (2005). Unwilling versus unable: Infants' understanding of intentional action. Developmental Psychology, 41(2), 328-337.

Bellagamba, F., \& Tomasello, M. (1999). Re-enacting intended acts: Comparing 12-and 18-month-olds. Infant Behavior and Development, 22(2), 277-282.
Bertenthal, B. (1996). Origins and early development of perception, action, and representation. Annual Review of Psychology, 47, 431-459.

Bickerton, D. (2005). Language first, then shared intentionality, then a beneficent spiral. Behavioral and Brain Sciences, 28(5), 691-692.

Boesch, C. (2005). Joint cooperative hunting among wild chimpanzees: Taking natural observations seriously. Behavioral and Brain Sciences, 28(5), 692-693.

Brownell, C. A., Nichols, S., \& Svetlova, M. (2005). Early development of shared intentionality with peers. Behavioral and Brain Sciences, 28(5), 693-694.

Bruner, J. (2005). Homo sapiens, a localized species. Behavioral and Brain Sciences, 28(5), 694-695.

Carpenter, M., Akhtar, N., \& Tomasello, M. (1998). Fourteenthrough 18-month-old infants differentially imitate intentional and accidental actions. Infant Behavior and Development, 21(2), 315-330.

Charman, T. (2005). Why do individuals with autism lack the motivation or capacity to share intentions? Behavioral and Brain Sciences, 28(5), 695-696.

Chomsky, N. (1967). A Review of B. F. Skinner's Verbal Behavior. Em L. A. Jakobovits \& M. S. Miron (Eds.), Readings in the Psychology of Language (pp. 142-143). Englewood Cliffs: Prentice-Hall. (Trabalho original publicado em 1959)

Chomsky, N. (1968). Language and mind. New York: Harcourt Brace Jovanovich.

Chomsky, N. (1980). Rules and representations. Behavioral and Brain Sciences, 3(1), 1-61.

D’Entremont, B., Hains, S. M. J., \& Muir, D. W. (1997). A demonstration of gaze following in 3- to 6-month-olds. Infant Behavior and Development, 20(4), 569-572.

Gauvain, M. (2005). What are the consequences of understanding the complex goal-directed actions of others? Behavioral and Brain Sciences, 28(5), 700-701.

Gergely, G., Bekkering, H., \& Kiraly, I. (2002). Rational imitation in preverbal infants. Nature, 415(6873), 755.

Hatano, G., \& Takahashi, K. (2005). Is shared intentionality widespread among and unique to humans? Behavioral and Brain Sciences, 28(5), 703.

Hauser, M. D., Chomsky, N., \& Fitch, W. T. (2002). The faculty of language: What is it, who has it, and how did it evolve? Science, 298(5598), 1569-1579.

Horner, V., Bonnie, K. E., \& de Waal, F. B. M. (2005). Identifying the motivations of chimpanzees: Culture and collaboration. Behavioral and Brain Sciences, 28(5), 704-705.

Meltzoff, A. N. (1995). Understanding the intentions of others: Re-enactment of intended acts by 18-month-old children. Developmental Psychology, 31(5), 838-850.

Moll, H., \& Tomasello, M. (2004). Twelve- and 18-monthold infants follow gaze to spaces behind barriers. Developmental Science, 7(1), F1-F9.

Perner, J., \& Doherty, M. (2005). Do infants understand that external goals are internally represented? Behavioral and Brain Sciences, 28(5), 710-711.

Pinker, S. (1994). The language instinct. New York: William Morrow.

Povinelli, D. J., \& Barth, J. (2005). Reinterpreting behavior: A human specialization? Behavioral and Brain Sciences, 28(5), 712-713. 
Schuster, R. (2005). Why not chimpanzees, lions, and hyenas too? Behavioral and Brain Sciences, 28(5), 716-717.

Souza, C. B. A. (2001). Adquisición de competencias linguísticas: Una propuesta de análisis funcional. Tese de Doutorado, Universidad de Guadalajara, México.

Souza, C. B. A. (2003). Uma proposta de análise funcional da aquisição da linguagem: resultados iniciais. Interação em Psicologia, 7(1), 83-91.

Souza, C. B. A., \& Pontes, S. S. (2007). Variações paramétricas em pré-requisitos da linguagem: estudo longitudinal das interações criança-acompanhante. Interação em Psicologia, 11(1), 55-70.

Tomasello, M. (2003a). Origens culturais da aquisição do conhecimento humano. (C. Berliner, Trad.) São Paulo: Martins Fontes. (Trabalho original publicado em 1999)

Tomasello, M. (2003b). Constructing a language: A usagebased theory of language acquisition. Cambridge: Harvard University Press.

Tomasello, M., \& Call, J. (1997). Primate cognition. Oxford: Oxford University Press.

Tomasello, M., Carpenter, M., Call, J., Behne, T., \& Moll, H. (2005a). In search of the uniquely human. Behavioral and Brain Sciences, 28(5), 721-727.

Tomasello, M., Carpenter, M., Call, J., Behne, T., \& Moll, H. (2005b). Understanding and sharing intentions: The origins of cultural cognition. Behavioral and Brain Sciences, 28(5), 675691.
Tomasello, M., \& Haberl, K. (2003). Understanding attention: 12- and 18-month olds know what is new for other persons. Developmental Psychology, 39(5), 906-912.

Tomasello, M., Kruger, A. C., \& Ratner, H. H. (1993). Cultural learning. Behavioral and Brain Sciences, 16(3), 495-552.

Vaish, A., \& Woodward, A. L. (2005). Baby steps on the path to understanding intentions. Behavioral and Brain Sciences, 28(5), 717-718.

Verbeke, E., Peeters, W., Kerkhof, I., Bijttebier, P., Steyaert, J., \& Wagemans, J. (2005). Lack of motivation to share intentions: Primary deficit in autism? Behavioral and Brain Sciences, 28(5), 718-719.

Watson, J. (2005). “Einstein's baby” could infer intentionality. Behavioral and Brain Sciences, 28(5), 719-720.

Woodward, A. L. (1998). Infants selectively encode the goal object of an actor's reach. Cognition, 69(1), 1-34.

Zlatev, J., Persson, T., \& Gärdenfors, P. (2005). Triadic bodily mimesis is the difference. Behavioral and Brain Sciences, 28(5), 720-721. 